\title{
High survival frequencies at low herbicide use rates in populations of Lolium rigidum result in rapid evolution of herbicide resistance
}

\author{
P Neve and S Powles \\ Western Australian Herbicide Resistance Initiative, School of Plant Biology, University of Western Australia, Crawley, \\ WA 6009, Australia
}

\begin{abstract}
The frequency of phenotypic resistance to herbicides in previously untreated weed populations and the herbicide dose applied to these populations are key determinants of the dynamics of selection for resistance. In total, 31 Lolium rigidum populations were collected from sites with no previous history of exposure to herbicides and where there was little probability of gene flow from adjacent resistant populations. The mean survival frequency across all 31 populations following two applications of commercial rates (375 $\mathrm{g} \mathrm{ha}^{-1}$ ) of the acetyl-coenzyme A carboxylase (ACCase) inhibiting herbicide, diclofop-methyl was $0.43 \%$. Survivors from five of these populations were grown to maturity and seed was collected. Dose-response experiments compared population level resistance to diclofop-methyl in these
\end{abstract}

selected lines with their original parent populations. A single cycle of herbicide selection significantly increased resistance in all populations ( $L D_{50} R: S$ ratios ranged from 2.8 to 23.2), confirming the inheritance and genetic basis of phenotypic resistance. In vitro assays of ACCase inhibition by diclofop acid indicated that resistance was due to a non-target-site mechanism. Following selection with diclofop-methyl, the five $L$. rigidum populations exhibited diverse patterns of crossresistance to ACCase and ALS-inhibiting herbicides, suggesting that different genes or gene combinations were responsible for resistance. The relevance of these results to the management of herbicide resistance are discussed. Heredity (2005) 95, 485-492. doi:10.1038/sj.hdy.6800751; published online 21 September 2005

Keywords: herbicide resistance; evolution; selection intensity; gene frequencies; cross-resistance

\section{Introduction}

Evolved herbicide resistance now compromises crop weed management throughout the world (reviewed in Powles and Shaner, 2001). The dynamics of herbicide resistance evolution are governed by the biology of weedy plant species, by the genetic determination of the resistance trait and by herbicide characteristics and use patterns. Genetic factors include the frequency, dominance and inheritance of major (large phenotypic effect) and minor (small phenotypic effect) resistance-endowing alleles and the fitness of resistant genotypes in the presence and absence of the selecting agent (reviewed by Georghiou and Taylor, 1986; Maxwell and Mortimer, 1994; Jasieniuk et al, 1996). Important herbicide-related factors include herbicidal mode of action, environmental persistence and frequency of use. The role of herbicide dose in determining the evolutionary dynamics of herbicide resistance has often not been fully considered. Where high herbicide doses are applied, only those individuals possessing resistance alleles conferring a high level of resistance (major alleles) will survive and frequencies of resistance to these high doses will likely be low. Conversely, as dose is reduced, other weaker

Correspondence: P Neve. Current address: Warwick HRI, University of Warwick, Wellesbourne, Warwickshire CV35 9EF, UK.

E-mail: p.neve@warwick.ac.uk

Received 25 November 2004; accepted 22 July 2005; published online 21 September 2005 resistance mechanisms (minor alleles) will enable survival, and observed frequencies of putative herbicide resistance will be higher. Neve and Powles (2005) have demonstrated that under recurrent selection at low herbicide doses, Lolium rigidum is able to rapidly evolve high levels of resistance as multiple weaker mechanisms are selected and enriched.

Changes in herbicide target-site sensitivity conferred by point mutations at single major genes (target-site resistance) account for the majority of documented fieldevolved herbicide resistance (reviewed by Darmency, 1994; Jasieniuk et al, 1996; Tranel and Wright, 2002). Rates of spontaneous mutation vary from organism to organism and from locus to locus, ranging from $10^{-7}$ mutations per base pair per replication in some bacteriophages to $10^{-11}$ per base pair per replication in humans (Drake et al, 1998). Relatively little is known of per locus rates of mutation in planta, although for herbicide resistance, Haughn and Somerville (1987) estimated the spontaneous rate of target-site acetolactate synthase (ALS) gene mutations in Arabidopsis thaliana to be of the order of $10^{-9}$. In unselected, herbicide susceptible weed populations, major resistance alleles will be at a mutation-selection equilibrium determined by the mutation rate and the selective disadvantage of the mutant alleles. Modelling studies that simulate herbicide resistance evolution in the field usually assume initial major resistance allele frequencies of between $10^{-7}$ and $10^{-5}$ (Gressel and Segel, 1978; Diggle et al, 2003). Preston and Powles (2002) measured frequencies 
between $1 \times 10^{-5}$ and $1.2 \times 10^{-4}$ for target-site ALS herbicide resistant mutants in three unselected $L$. rigidum populations.

In addition to variation at major resistance genes, continuous and heritable variation in susceptibility to low herbicide rates has been documented in weed populations (see Holliday and Putwain 1980; Jasieniuk et al, 1996; Patzoldt et al, 2002). While the genetic basis for this variation is not reported, continuous variation usually indicates polygenic control at numerous minor loci. Rates of spontaneous mutation at minor loci influencing a quantitative trait are approximately $10^{-2}$ per gamete per generation (Lande, 1983) and in view of this, we may expect more variation in herbicide susceptibility at minor, compared with major loci in populations not previously exposed to herbicides, resulting in quantitative variation in herbicide susceptibility. Where pesticide selection pressure acts within the normal range of continuous phenotypic variation for pesticide sensitivity, variation at minor resistance-endowing loci may be enriched and responses to selection will be polygenic (McKenzie and Batterham 1994; McKenzie, 2000).

The annual grass species, L. rigidum is the most severe weed of Australian agriculture. Since the 1970s, L. rigidum control has been dominated by herbicides and many populations have evolved multiple- and crossresistance (Burnet et al, 1994; Preston et al, 1996; Neve et al, 2004), in some cases after as few as 3-4 herbicide applications (Gill 1995). In a large random survey conducted in 1998, $46 \%$ of L. rigidum populations were resistant to field application rates of the acetyl-coenzyme A caboxylase (ACCase) inhibiting herbicide diclofopmethyl (Llewellyn and Powles, 2001). Reasons for the unprecedented scale and rapid evolution of resistance to ACCase and other herbicides in Australian L. rigidum populations are not fully understood. In Australia, large farm sizes, low yields and small per area profit margins mean that herbicide application rates are often lower than elsewhere in the world. We postulate that these relatively low herbicide use rates select for variation in diverse nontarget site resistance mechanisms, which are initially present at high frequencies in unselected $L$. rigidum populations. Under recurrent herbicide selection, these unspecified mechanisms will accumulate and result in the rapid evolution of herbicide resistance.

This study quantifies variation in the levels of susceptibility to field applied rates of diclofop-methyl in $31 \mathrm{~L}$. rigidum populations with no history of herbicide treatment. The response to selection with diclofopmethyl and the mechanistic basis of resistance is described for five of these populations and is discussed in terms of observed patterns of herbicide resistance for this species in Australia.

\section{Materials and methods}

\section{Plant material}

Seeds of $31 \mathrm{~L}$. rigidum populations were collected from sites in Western Australia (16), Victoria (12) and South Australia (3) in 2001. Collection sites (waste ground, roadsides, parkland and unimproved pasture) were selected to minimize the likelihood of previous exposure to ACCase herbicides and to ensure that there was very little chance of gene flow from herbicide treated areas. In
Western Australia all sites were more than $50 \mathrm{~km}$ from agricultural areas where these herbicides were used. In South Australia and Victoria, farmers were consulted to ensure that adjacent agricultural fields had no history of herbicide application. At each site seed was harvested from at least 50 individual plants. After collection, seed was stored under hot, dry summer conditions with fluctuating day/night temperatures to facilitate dormancy release. During April 2002, seed was threshed and cleaned and was stored at constant $20^{\circ} \mathrm{C}$ until use.

\section{Screen for diclofop-methyl resistance}

In May 2002, 400-500 seeds of each of the 31 populations (four replicates) were evenly spread onto the surface of seedling trays $\left(28 \times 33 \times 5 \mathrm{~cm}^{3}\right)$ containing a standard potting mixture (50\% peat:50\% sand). Seeds were covered with a $2 \mathrm{~mm}$ layer of potting mixture. Trays were maintained in a cooled glasshouse (maximum daily temperature $20 \pm 5^{\circ} \mathrm{C}$ ) and were watered on a daily basis. At the 2-3 leaf stage, the number of emerged seedlings was counted and the commercial herbicide diclofopmethyl plus $0.25 \%$ of BS1000 nonionic surfactant was applied at the Australian use rate for L. rigidum control $\left(375 \mathrm{~g} \mathrm{ha}^{-1}\right)$. The herbicide was applied using a twin nozzle laboratory sprayer delivering herbicide in $1001 \mathrm{ha}^{-1}$ of water at $210 \mathrm{kPa}$ when travelling at $1 \mathrm{~m} \mathrm{~s}^{-1}$. Trays were returned to the glasshouse after herbicide application. Initial assessments of plant survival were made 21 days after herbicide treatment. The shoots of surviving plants were cut back to soil level and were allowed to regrow for 5 days. At this stage, diclofopmethyl was reapplied as described above. Plant survival was reassessed 21 days after the second herbicide application. Plants were scored as alive if they had resumed growth after cutting and continued to grow after the second herbicide application. The total number of treated and surviving plants was summed across the four replicates and percentage survival was calculated for each population.

Surviving plants from five populations (Busselton 1, Busselton 2, Gnangara, Kudardup, Victoria 9) were excavated from trays, individually repotted in $180 \mathrm{~mm}$ plastic pots and grown to maturity in the glasshouse. Prior to anthesis, each population was isolated to one bench in the glasshouse and plants were surrounded by a pollen-proof enclosure to ensure cross-pollination within populations only. At maturity, seed was harvested and stored over summer as described previously.

\section{Response to diclofop-methyl selection}

In July 2004, dose-response experiments were conducted to compare levels of survival in the diclofop-methyl selected progeny and their original unselected parent populations. Seeds (12) of the original Busselton 1, Busselton 2, Gnangara, Kudardup and Victoria 9 populations and their diclofop-methyl selected progeny (for example, denoted as Busselton $1^{+}$to indicate a selected line) were sown into $180 \mathrm{~mm}$ pots containing standard potting mixture and were maintained in the glasshouse as described previously. At the 2-3 leaf stage, emerged seedlings were sprayed with diclofop-methyl at $0,47,94,188,375,750,1500$ or $3000 \mathrm{~g} \mathrm{ha}^{-1}$ using the laboratory sprayer. There were three replicate pots per treatment. 
Plant survival was assessed 21 days after herbicide treatment (plants were scored as alive if they had continued to grow following herbicide treatment) and percentage survival was calculated for each population by herbicide dose treatment. Survival data were analysed by probit analysis. Values for percentage survival were converted to probits and the function, probit $=$ $a \log _{10}($ dose $)+b$ was fitted to the transformed data (Genstat version 6.1.0.200), where $a$ is the slope of the line and $b$ the intercept. The $\operatorname{LD}_{50}$ values (diclofopmethyl dose causing 50\% mortality), together with $95 \%$ confidence intervals, were calculated from probit analysis. The shoots of surviving and dead plants were harvested at the soil surface and fresh weight of all individuals was recorded. The mean shoot weight of treated individuals was calculated for each population by dose treatment and was expressed as a percentage of the mean fresh weight of untreated individuals for that population. These data were analysed by nonlinear regression (Genstat version 6.1.0.200) and fitted to the log-logistic model:

$$
y=\frac{100}{1+\exp \left[b\left(x-x_{50}\right)\right]}
$$

where $y$ is the fresh biomass (\% of mean untreated control), $x_{50}$ is the $\log$ of the dose required to reduce growth by $50 \%$ and $b$ is the slope around $x_{50}$. The diclofop-methyl dose required to reduce mean fresh above-ground biomass by $50 \%\left(\mathrm{GR}_{50}\right)$ was calculated by back-transforming $x_{50}$.

\section{ACCase extraction and assay}

In vitro assays of ACCase inhibition by diclofop acid were performed to determine if observed changes in resistance following selection with diclofop-methyl were the result of reduced sensitivity of the herbicide target enzyme. Seeds of the unselected $L$. rigidum populations and of their diclofop-methyl selected lines were sown into three replicate $180 \mathrm{~mm}$ pots per line (20 per pot) and were maintained in a glasshouse. At the 1.5-2 leaf stage, plants were harvested at the soil level and fresh shoot material was frozen in liquid nitrogen and stored at $-20^{\circ} \mathrm{C}$ until use. Crude enzyme was extracted from a sample of shoot tissue $(3 \mathrm{~g})$ for each L. rigidum line and enzyme activity was assayed in duplicate over a range of diclofop acid concentrations.

Frozen tissue was homogenized in $10 \mathrm{ml}$ extraction buffer containing $100 \mathrm{mM}$ Tris ( $\mathrm{pH}$ 8.0), $1 \mathrm{mM}$ EDTA, $10 \%$ (v/v) glycerol, $2 \mathrm{mM}$ isoascorbic acid, $1 \mathrm{mM}$ PMSF, $0.5 \%$ PVP-40, 0.5\% insoluble PVP, and $20 \mathrm{mM}$ DTT. The homogenate was centrifuged at $27000 \mathrm{~g}$ for $15 \mathrm{~min}$. The supernatant was brought to $40 \%\left(\mathrm{NH}_{4}\right)_{2} \mathrm{SO}_{4}$ saturation by dropwise addition of saturated $\left(\mathrm{NH}_{4}\right)_{2} \mathrm{SO}_{4}$ and stirred for $30 \mathrm{~min}$. The solution was centrifuged at $27000 \mathrm{~g}$ for $30 \mathrm{~min}$. The pellet was resuspended in $2.5 \mathrm{ml}$ elution buffer $\left(50 \mathrm{mM}\right.$ Tricine, $\mathrm{pH} 8.0,2.5 \mathrm{mM} \mathrm{MgCl}_{2}, 50 \mathrm{mM}$ $\mathrm{KCl}, 1 \mathrm{mM}$ DTT) and desalted on a Sephadex G-25 (Pharmacia PD-10) column pre-equilibrated with elution buffer. The eluent was stored at $-20^{\circ} \mathrm{C}$ until use (modified from Tardif et al, 1993).

ACCase activity was assayed by quantifying the incorporation of $\mathrm{NaH}^{14} \mathrm{CO}_{3}$ into an acid-stable product according to Seefeldt et al (1996) with modifications. The enzyme extract was incubated at $30^{\circ} \mathrm{C}$ in assay buffer that contained $10 \mathrm{mM}$ Tricine- $\mathrm{KOH}, \mathrm{pH} 8.3,5 \mathrm{mM}$ ATP, $10 \mathrm{mM} \mathrm{MgCl}_{2}, 0.1 \%$ BSA, $2.5 \mathrm{mM}$ DTT, $3.24 \mathrm{mM} \mathrm{NaHCO}_{3}$ (including $18.5 \mathrm{kBq}$ of $\mathrm{NaH}^{14} \mathrm{CO}_{3}$ ) and appropriate concentrations of technical grade diclofop acid. A diclofop acid concentration series $(0.1,1,10,50$ and $100 \mu \mathrm{M})$ was prepared in $100 \mathrm{mM}$ tricine buffer containing $10 \%$ acetone. The reaction was started by the addition of acetyl-CoA at a final concentration of $0.25 \mathrm{mM}$ and was stopped after $10 \mathrm{~min}$ by the addition of concentrated $\mathrm{HCl}$. A $50 \mu \mathrm{l}$ aliquot of the reaction mixture was placed on glass filter paper and air-dried. After drying, the filter paper was placed in a scintillation vial containing $3 \mathrm{ml}$ of liquid scintillant. Radioactivity was determined using a liquid scintillation counter. Enzyme activity (inhibition) was expressed as a percentage of the untreated control and results were analysed by log-logistic regression analysis (equation (1)) to determine and compare the $I_{50}$ values (diclofop acid concentration required to reduce enzyme activity by $50 \%$ ) of the ACCase enzyme from diclofop-methyl selected and unselected lines. Pairwise comparisons of the $I_{50}$ values of unselected and selected lines were performed using $t$-test.

\section{Cross-resistance profiling}

In August 2004, an experiment was established to determine levels of cross-resistance to four ACCase-inhibiting (fluazifop-P-butyl, haloxyfop-R-methyl, sethoxydim and tepraloxydim) and two ALS-inhibiting herbicides (chlorsulfuron and imazethapyr). Seeds (10) of the diclofop-methyl selected and unselected lines were sown in seedling trays containing a standard potting mixture and were placed on benches in an outdoor experimental garden at the University of Western Australia (three replicates per treatment). Trays were watered and fertilized as required. At the 2-3 leaf stage, emerged seedlings were counted and herbicides were applied at two rates (referred to as low and intermediate rates) using the laboratory sprayer. The herbicides applied and their application rates are in Table 1 . Herbicide rates were selected on the basis of prior knowledge of normal responses of susceptible L. rigidum populations. Intermediate rates would usually result in 100\% mortality of susceptible $L$. rigidum and low rates in low levels $(<10 \%)$ of survival. Rates for the two ALS-inhibiting herbicides were higher than field recommended rates

Table 1 Herbicides and rates applied to diclofop-methyl selected and unselected L. rigidum lines for cross-resistance profiling

\begin{tabular}{lccc}
\hline Herbicide active ingredient & $\begin{array}{c}\text { Low rate } \\
\left(\mathrm{g} \mathrm{ha}^{-1}\right)\end{array}$ & $\begin{array}{c}\text { Intermediate } \\
\text { rate }\left(\mathrm{g} \mathrm{ha}^{-1}\right)\end{array}$ & $\begin{array}{c}\text { Recommended } \\
\text { use rate } \\
\left(\mathrm{gha}^{-1}\right)\end{array}$ \\
\hline Fluazifop-P-butyl $^{\mathrm{a}}$ & 27 & 53 & 53 \\
Haloxyfop-R-methyl $^{\mathrm{a}}$ & 14 & 29 & 39 \\
Sethoxydim $^{\mathrm{b}}$ & 33 & 70 & 93 \\
Tepraloxydim $^{\mathrm{b}}$ & 18 & 38 & 50 \\
Chlorsulfuron $^{\mathrm{c}}$ & 30 & 120 & 15 \\
Imazethapyr $^{\mathrm{d}}$ & 70 & 175 & 70 \\
\hline
\end{tabular}

aryloxyphenoxypropionate (ACCase inhibitor).

${ }^{b}$ Cyclohexanedione (ACCase inhibitor).

sulfonylurea (ALS inhibitor).

${ }^{\mathrm{d}}$ Imidazolinone (ALS inhibitor). 
based on relatively poor control of L. rigidum by these herbicides when applied to seedlings post-emergence in pot trials. Plant survival was assessed 21 days after herbicide treatment. Plants were assessed as previously described and mean percentage survival $(n=3)$ was calculated. The relative survival of the diclofop-methyl selected lines was calculated as the difference in survival of the selected and unselected lines for each herbicide rate.

\section{Results}

Frequency of phenotypic resistance to diclofop-methyl in unselected $L$. rigidum

Between 600 and 1500 individuals of each of 31 unselected L. rigidum populations were treated with the commercial rate $\left(375 \mathrm{~g} \mathrm{ha}^{-1}\right)$ of diclofop-methyl (differences in the total numbers of treated individuals reflected variations in seed germination and emergence of the populations). As expected, there was high mortality and the mean frequency of survivors was $4.3 \times 10^{-3}(0.43 \%)$ (Table 2). The highest frequency of survivors was observed for the Western Australian population, Augusta 2, in which $2.6 \%(n=24)$ of sprayed individuals survived. There were no survivors in six of the populations screened. The significance of these

Table 2 Frequencies of survival of previously unselected populations of L. rigidum from Western Australia (WA), Victoria and South Australia (SA) following application of diclofop-methyl

\begin{tabular}{|c|c|c|c|}
\hline Population & Plants treated & Plants survived & $\%$ survival \\
\hline Augusta 2 (WA) & 914 & 24 & 2.6 \\
\hline Bordertown (SA) & 1320 & 17 & 1.3 \\
\hline Busselton 2 (WA) & 1170 & 13 & 1.1 \\
\hline Nannup 3 (WA) & 1065 & 10 & 0.95 \\
\hline Gnangara (WA) & 992 & 9 & 0.91 \\
\hline$\overline{\mathrm{M} \text { River } 2}$ (WA) & 1459 & 10 & 0.69 \\
\hline Busselton 1 (WA) & 1104 & 7 & 0.63 \\
\hline Kudardup (WA) & 1227 & 6 & 0.49 \\
\hline$\overline{\text { Augusta } 1}$ (WA) & 1047 & 5 & 0.48 \\
\hline Victoria 15 & 848 & 4 & 0.47 \\
\hline M River 1 (WA) & 1284 & 6 & 0.47 \\
\hline Calgardup (WA) & 609 & 2 & 0.33 \\
\hline Swan Valley (WA) & 926 & 3 & 0.32 \\
\hline Victoria 8 & 1255 & 4 & 0.32 \\
\hline Victoria 9 & 1419 & 4 & 0.28 \\
\hline Spring Gully (SA) & 1175 & 3 & 0.26 \\
\hline Blessing (SÂ) & 1213 & 3 & 0.25 \\
\hline Victoria 18 & 1183 & 3 & 0.25 \\
\hline Victoria 2 & 1109 & 2 & 0.18 \\
\hline Swan (WA) & 1300 & 2 & 0.15 \\
\hline Victoria 21 & 948 & 1 & 0.11 \\
\hline Victoria 5 & 1054 & 1 & 0.10 \\
\hline Northcliffe (WA) & 1041 & 1 & 0.10 \\
\hline Pemberton (WA) & 989 & 1 & 0.10 \\
\hline Victoria 12 & 1117 & 1 & 0.09 \\
\hline Denmark (WA) & 807 & 0 & 0 \\
\hline Cowaramup (WA) & 1126 & 0 & 0 \\
\hline Victoria 13 & 1128 & 0 & 0 \\
\hline Victoria 6 & 1032 & 0 & 0 \\
\hline Victoria 4 & 732 & 0 & 0 \\
\hline Victoria 20 & 1188 & 0 & 0 \\
\hline Total & 32700 & 141 & 0.43 \\
\hline
\end{tabular}

Survivors from underlined populations were grown to maturity to produce diclofop-methyl selected lines. results for the evolution of herbicide resistance and its subsequent management will depend on the relative contribution of genetic and environmental factors to this putative phenotypic resistance. In order to confirm that plant survival was the result of heritable genetic variation, survivors from five of the previously unselected populations were grown to maturity, and each population was individually bulk-crossed to produce a diclofop-methyl selected line. The response to selection and heritability of resistance within the five populations was tested by detailed dose-response experiments.

\section{Dose-response of diclofop-methyl selected L. rigidum populations}

Large differences in the dose-response characteristics of diclofop-methyl selected and unselected lines of five $L$. rigidum populations confirmed that high initial levels of survival to field recommended rates of diclofop-methyl were the result of heritable variations in herbicide sensitivity. The $\mathrm{LD}_{50}$ values (Table 3) for the unselected lines ranged from 75 to $127 \mathrm{gha}^{-1}$ diclofop-methyl and from 361 to $1924 \mathrm{~g} \mathrm{ha}^{-1}$ following diclofop-methyl selection. There was little correlation between the initial population $\mathrm{LD}_{50}$ value and the response to selection. For example, Busselton 2, the population with the highest initial $\mathrm{LD}_{50}$ showed the weakest response to selection (R:S resistance ratio of 2.8, see Table 3).

Log-logistic analysis of fresh biomass data has adequately described the response of selected and unselected lines to diclofop-methyl $\left(R^{2}=0.551-0.975\right.$, Figure 1). $G_{50}$ values are summarized in Table 4 and while these confirm the populations responses to selection, there are some noteworthy differences in $\mathrm{LD}_{50}$ and $\mathrm{GR}_{50}$ values. For instance, there is a large difference between the $\mathrm{LD}_{50}$ (1924g diclofopmethyl ha ${ }^{-1}$ ) and $\mathrm{GR}_{50}$ (751 g diclofop-methyl ha ${ }^{-1}$ ) values for the Kudardup ${ }^{+}$line, indicating that the growth of individuals surviving herbicide treatments is significantly retarded. Conversely, there is little difference in the $\mathrm{LD}_{50}$ and $\mathrm{GR}_{50}$ values for the Busselton $1^{+}$ line. While it is clear that the variations in herbicide sensitivity observed in the initial resistance screen (Table 2) are heritable, the actual magnitude of the response to selection varies significantly between

Table 3 Diclofop-methyl dose required to cause 50\% mortality $\left(\mathrm{LD}_{50}\right)$ for diclofop-methyl unselected and selected lines

\begin{tabular}{|c|c|c|c|}
\hline \multirow[t]{2}{*}{ Population } & \multicolumn{2}{|c|}{$L D_{50}(g$ diclofop-methyl ha-1) } & \multirow[t]{2}{*}{$L D_{50} R: S$ ratio } \\
\hline & Unselected & Selected & \\
\hline on 1 & 95.6 & $1279(90$ & 13.4 \\
\hline Busselton 2 & 127 (103-155) & $361(276-472)$ & 2.8 \\
\hline Gnangara & $74.9(54.9-94.8)$ & $386(293-510)$ & 5.2 \\
\hline Kudardup & $82.9(64.3-102)$ & $1924(1230-3890)$ & 23.2 \\
\hline Victoria 9 & $101(76.0-128)$ & $623(506-773)$ & 6.2 \\
\hline
\end{tabular}

$\mathrm{LD}_{50}$ estimates are back-transformed from probit analysis of diclofop-methyl dose-mortality response data. 95\% confidence intervals are in parentheses.

${ }^{a} L D_{50} R: S$ ratios are calculated as the ratio of the $\mathrm{LD}_{50}$ of the selected and unselected lines. 


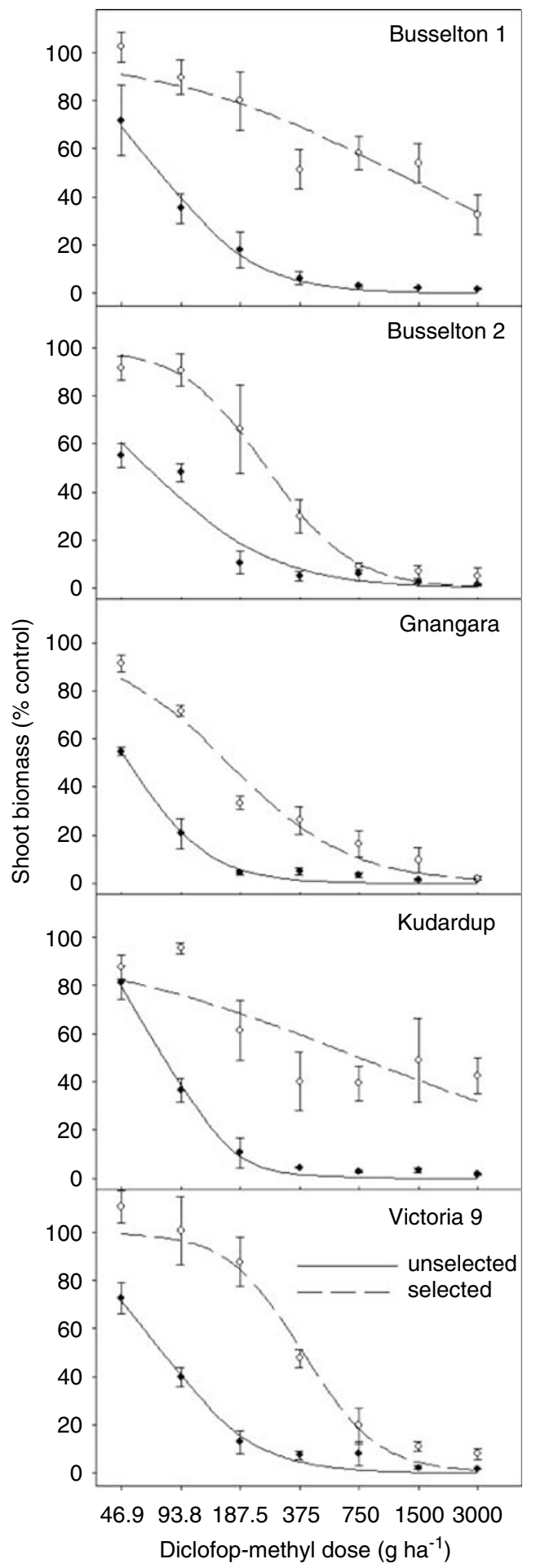

Figure 1 Dose-response curves for above-ground fresh biomass production (\% mean untreated control) 21 days after herbicide application for diclofop-methyl unselected and selected lines of five L. rigidum populations following application of diclofop-methyl at the 2-3 leaf stage. Symbols are mean observed \% biomass production and error bars are \pm one standard error of the mean. Predicted values for \% biomass production (solid and broken lines) are derived from log-logistic regression analysis.

populations. These observations suggest that there may be physiological and genetic differences in the underlying mechanism(s) of these responses.
Table 4 Diclofop-methyl dose required to reduce population fresh biomass by $50 \%\left(\mathrm{GR}_{50}\right)$ for diclofop-methyl unselected and selected lines

\begin{tabular}{|c|c|c|c|}
\hline \multirow[t]{2}{*}{ Population } & \multicolumn{2}{|c|}{$G R_{50}(g$ diclofop-methyl ha-1) } & \multirow[t]{2}{*}{$G_{50} R: S$ ratio } \\
\hline & Unselected & Selected & \\
\hline Busselton 1 & $74.8(6.9)$ & 1151 (297) & 15.4 \\
\hline Busselton 2 & $65.1(6.1)$ & $256(26.7)$ & 3.9 \\
\hline Gnangara & $51.9(2.7)$ & $163(14.4)$ & 3.1 \\
\hline Kudardup & $79.6(5.8)$ & 751 (275) & 9.4 \\
\hline Victoria 9 & $77.5(6.8)$ & $392(40.9)$ & 6.2 \\
\hline
\end{tabular}

$\mathrm{GR}_{50}$ estimates are back-transformed from log-logistic regression analysis. Standard errors of the estimates are in parentheses.

${ }^{a} G R_{50} R: S$ ratios are calculated as the ratio of the $G_{50}$ of the selected and unselected lines.

Table 5 Diclofop acid concentration required to cause $50 \%$ inhibition of acetyl-coenzyme A carboxylase activity $\left(I_{50}\right)$ for unselected and selected lines

\begin{tabular}{llc}
\hline Population & \multicolumn{2}{c}{$I_{50}(\mu M$ diclofop acid $)$} \\
\cline { 2 - 3 } & Unselected & Selected \\
\hline Busselton 1 & $4.30(0.57)$ & $6.17(0.91)$ \\
Busselton 2 & $5.51(0.70)$ & $4.31(0.58)$ \\
Gnangara & $7.13(1.33)$ & $5.02(0.86)$ \\
Kudardup & $5.26(1.40)$ & $5.21(0.56)$ \\
Victoria 9 & $4.61(0.49)$ & $4.30(0.77)$ \\
\hline
\end{tabular}

$I_{50}$ estimates are back-transformed from log-logistic regression analysis. Standard errors of the estimates are in parentheses. $I_{50}$ values of unselected and selected lines were compared by $t$-test and were not statistically different for any population.

In vitro inhibition of ACCase by diclofop acid

There were no significant differences in the in vitro diclofop acid inhibition of ACCase from unselected and diclofop-methyl selected lines (Table 5). These results established that observed increases in population level resistance were not target-site enzyme related due to any change in ACCase sensitivity, and must therefore be conferred by unknown nontarget site mechanism(s).

\section{Cross-resistance to other herbicides}

The resistance status of selected and unselected lines to four ACCase and two ALS-inhibiting herbicides was tested to establish patterns of cross-resistance following a single selection with diclofop-methyl. Relative survival was calculated by subtracting the survival $(\%)$ of original untreated lines from observed survival of diclofopmethyl selected lines (Figure 2). It was immediately evident that selection with diclofop-methyl increased population level resistance to other ACCase and ALS herbicides. Even more notable was that populations exhibited very diverse patterns of cross-resistance (Figure 2). The Busselton $1^{+}$and Kudardup ${ }^{+}$lines exhibit cross-resistance to low and intermediate levels of the aryloxyphenoxypropionate (AOPP) herbicides, fluazifop-P-butyl and haloxyfop-R-methyl, and the CHD herbicide sethoxydim, and very low-level cross-resistance to tepraloxydim. Interestingly, these two populations also exhibited the highest level of resistance to diclofop-methyl (Figure 1, Tables 3 and 4) suggesting that 
490

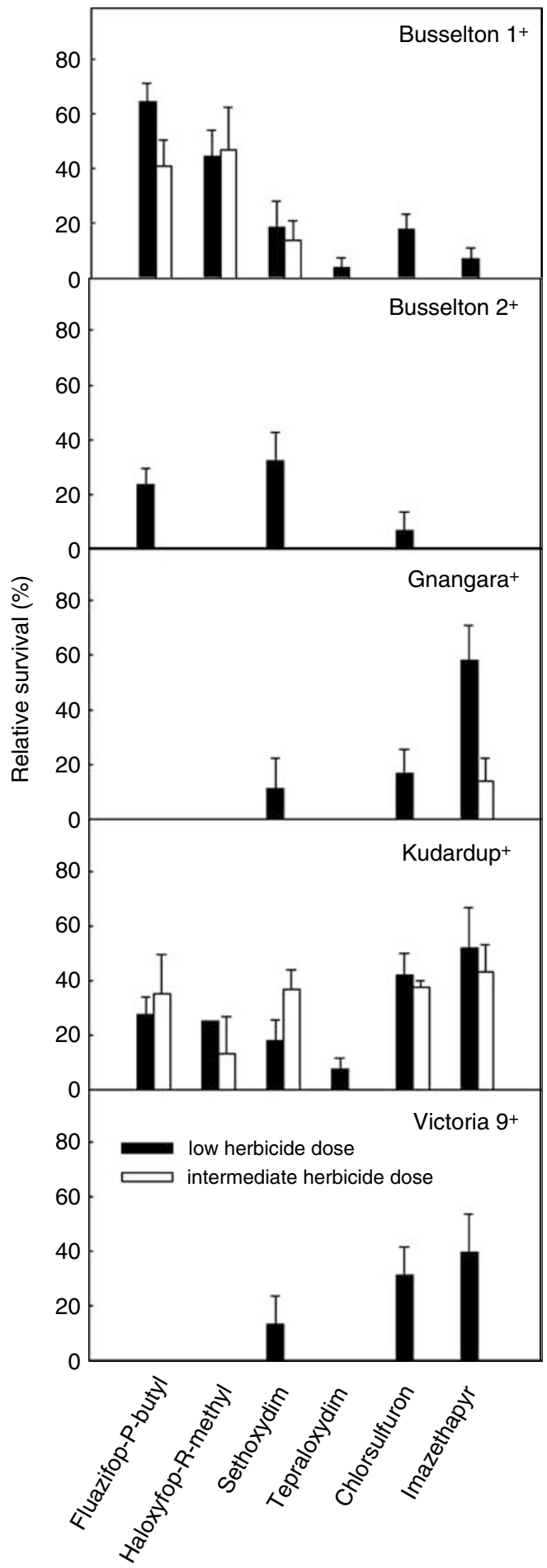

Figure 2 Mean percentage relative survival of diclofop-methyl selected lines of five $L$. rigidum populations treated with low and intermediate doses of ACCase and ALS-inhibiting herbicides (see Table 1). Relative survival is calculated by subtracting the survival (\%) of original untreated lines from observed survival of diclofopmethyl selected lines. Error bars are \pm one standard error of the mean.

their robust resistance to this herbicide confers diverse cross-resistance to other ACCase herbicides. The two populations did, however, differ in their cross-resistance to the ALS herbicides. Busselton $1^{+}$exhibited slight cross-resistance to chlorsulfuron and imazethapyr whereas Kudardup ${ }^{+}$demonstrated significant levels of resistance to low and intermediate rates of these two herbicides (Figure 2). The Gnangara ${ }^{+}$and Victoria 9+ lines had very low levels of cross-resistance to sethoxydim, but not to other ACCase inhibiting herbicides. They also had moderate resistance to chlorsulfuron and significant increases in survival at the low dose of imazethapyr. The Busselton $2^{+}$line exhibited moderate cross-resistance at low doses of fluazifop-P-butyl and sethoxydim and no resistance to the ALS-inhibiting herbicides. These widely contrasting patterns of crossresistance are intriguing as they further suggest that the precise mechanism and genetic basis of resistance in each selected line is different.

\section{Discussion}

Australian populations of L. rigidum have demonstrated rapid and widespread evolution of resistance to selective herbicides (Gill, 1995; Nietschke et al, 1996; Llewellyn and Powles, 2001). The potential for, and rate of evolved responses to herbicides depends on the existence within plant populations of genetic variation for responses to herbicides (survival and growth). The results reported here have clearly demonstrated high survival frequencies $($ mean $=0.43 \%$ ) in a number of pristine $L$. rigidum populations from across Australia following application of a commercial rate $\left(375 \mathrm{~g} \mathrm{ha}^{-1}\right)$ of the ACCase-inhibiting herbicide diclofop-methyl (Table 2). These results are similar to those reported by Matthews and Powles (1992), who found a mean diclofop-methyl survival frequency of $0.2 \%$ in a number of previously untreated L. rigidum populations from non-farm situations. For five of these populations we have demonstrated that this putative resistance was heritable (Tables 3 and 4 and Figure 1) and that resistance was not based on target-site insensitivity (Table 5). Additionally, a single cycle of selection with diclofop-methyl increased populationlevel resistance to a range of other herbicides (Figure 2), demonstrating the potential for rapid selection of diverse cross-resistance patterns. These observed phenotypic frequencies of resistance were orders of magnitude greater than rates of spontaneous target-site mutations, which give rise to target-site ALS resistance in Arabidopsis thaliana (Haughn and Somerville, 1987; Jander et al, 2003) and Nicotiana tabacum (Harms and DiMaio, 1991). These frequencies were also much greater than the initial frequency of target-site based resistance to ALS herbicides in three previously untreated L. rigidum populations (Preston and Powles, 2002).

The physiological and genetic basis of resistance has not been determined, although it is not due to single gene, target-site resistance (Table 5). Species-dependent variations in the rate and mechanism of detoxification of some herbicides are the basis of herbicide selectivity (Owen, 2000). Indeed, grass weed control in wheat by some ACCase herbicides is based on differential rates of herbicide metabolism mediated by the cytochrome $P 450$ and glutathione-S-transferase enzyme families (see Cole and Edwards, 2000). The evolution of enhanced rates of herbicide detoxification, mediated by cytochrome P450 monooxygenases, has previously been documented as a mechanism of evolved resistance to ACCase herbicides in L. rigidum (Preston et al, 1996) and Alopecurus 
myosuroides (Letouze and Gasquez, 2003). Glutathione transferases have also been shown to contribute to evolved herbicide resistance in $A$. myosuroides (Cummins et al, 1999). These and other potentially unknown mechanisms are expected to be responsible for resistance in our unselected L. rigidum populations. Plant cytochrome P450s are the largest family of plant proteins and are responsible for synthesising a vast array of plant secondary metabolites, many of which are involved in plant defence against biotic and abiotic stress (Morant et al, 2003). Likewise, the glutathione-S-transferases have long been associated with stress tolerance in plants (Frova 2003). We speculate that L. rigidum populations in Australia maintain a high level of genetic variability for expression and substrate specificity within these multifunctional enzyme families and that exposure to low herbicide rates selects for individuals with initially lowlevel resistance to herbicides. In an outcrossing species such as L. rigidum, all minor resistance mechanisms will be selected and enriched, and will accumulate in subsequent generations leading to polygenically endowed herbicide resistance.

The diverse patterns of cross-resistance observed in the five selected L. rigidum populations further suggested the involvement of different genes or gene combinations. This observation has significant management implications as it indicates that selection with a single herbicide can result in complex and highly unpredictable patterns of cross-resistance. Given this, the availability and efficacy of alternative herbicides for L. rigidum control may often be compromised following selection for resistance to diclofop-methyl (or other) herbicides. Finally, it is worth reiterating that herbicide use rates in Australia are generally lower than elsewhere in the world and that this may contribute to the prevalence of evolved resistance as use rates are selecting within the normal range of phenotypic variation for herbicide sensitivity. Our results should be borne in mind as economic and environmental incentives to reduce herbicide application rates continue to increase in some parts of the world.

\section{References}

Burnet MWM, Hart Q, Holtum JAM, Powles SB (1994). Resistance to nine herbicide classes in a population of rigid ryegrass (Lolium rigidum). Weed Sci 42: 369-377.

Cole DJ, Edwards R (2000). Secondary metabolism of agrochemicals in plants. In: Roberts TR (ed) Agrochemicals and Plant Protection. John Wiley \& Sons: Chichester, pp 107-154.

Cummins I, Cole DJ, Edwards R (1999). A role for glutathione transferases functioning as glutathione peroxidases in resistance to multiple herbicides in black-grass. Plant $J \mathbf{1 8}$ : 285-292.

Darmency H (1994). Genetics of herbicide resistance in weeds and crops. In: Powles SB, Holtum JAM (eds) Herbicide Resistance in Plants: Biology and Biochemistry. CRC Press: Baton Rouge, pp 263-298.

Diggle AD, Neve PB, Smith FP (2003). Herbicides used in combination can reduce the probability of herbicide resistance in finite weed populations. Weed Res 43: 371-382.

Drake JW, Charlesworth B, Charlesworth D, Crow JF (1998). Rates of spontaneous mutation. Genetics 148: 1667-1686.

Frova C (2003). The plant glutathione transferase gene family: genomic structure, functions, expression and evolution. Physiol Plantarum 119: 469-479.
Georghiou GP, Taylor CE (1986). Factors influencing the evolution of resistance. In: Pesticide Resistance: Strategies and Tactics or Management. National Academy Press: Washington, DC, pp 157-169.

Gill GS (1995). Development of herbicide resistance in annual ryegrass populations (Lolium rigidum Gaud.) in the cropping belt of Western Australia. Aust J Exp Agric 35: 67-72.

Gressel J, Segel LA (1978). The paucity of plants evolving genetic resistance to herbicides: possible reasons and implications. J Theor Biol 75: 349-371.

Harms CT, DiMaio JJ (1991). Primisulfuron herbicide resistant tobacco cell lines. Application of fluctuation test design to in vitro mutant selection with plant cells. J Plant Physiol 137: 513-519.

Haughn G, Somerville CR (1987). Selection for herbicide resistance at the whole plant level. In: LeBaron HM, Mimma $\mathrm{RO}$, Hineycutt RC, Duesing JH (eds) Biotechnology in Agricultural Chemistry. American Chemical Society: Washington, DC, pp 98-107.

Holliday RJ, Putwain PD (1980). Evolution of herbicide resistance in Senecio vulgaris: variation in susceptibility to simazine between and within populations. J Appl Ecol 17: 779-791.

Jander G, Baerson SR, Hudak JA, Gonzalez KA, Gruys KJ, Last RL (2003). Ethylmethanesulfonate saturation mutagenesis in Arabidopsis to determine frequency of herbicide resistance. Plant Physiol 131: 139-146.

Jasieniuk M, Brule-Babel AL, Morrison IA (1996). The evolution and genetics of herbicide resistance. Weed Sci 44: 176-193.

Lande R (1983). The response to selection on major and minor mutations affecting a metrical trait. Heredity 50: 47-65.

Letouze A, Gasquez J (2003). Enhanced activity of several herbicide-degrading enzymes: a suggetsed mechanism responsible for multiple-resistance in blackgrass (Alopecurus myosuroides Huds.). Agronomie 23: 601-608.

Llewellyn RS, Powles SB (2001). High levels of herbicide resistance in rigid ryegrass (Lolium rigidum) in the wheat belt of Western Australia. Weed Technol 15: 242-248.

Matthews JM, Powles SB (1992). Aspects of the population dynamics of selection for herbicide resistance in Lolium rigidum Gaud. Proceedings of the First International Weed Control Congress, Vol 2, pp 318-320.

Maxwell BD, Mortimer AM (1994). Selection for herbicide resistance. In: Powles SB, Holtum JAM (eds) Herbicide Resistance in Plants: Biology and Biochemistry. CRC Press Inc.: Baton Rouge, pp 1-27.

McKenzie JA (2000). The character or the variation: the genetic analysis of the insecticide-resistance phenotype B. Entomol Res 90: 3-7.

McKenzie JA, Batterham P (1994). The genetic, molecular and phenotypic consequences of selection for insecticide resistance. Trends Ecol Evol 9: 166-169.

Morant M, Bak S, Moller BL, Werck-Reichart D (2003). Plant cytochrome $P 450$ : tools for pharmacology, plant protection and phytoremediation. Curr Opin Biotech 14: 151-162.

Neve P, Powles SB (2005). Recurrent selection with suboptimal rates of the herbicide diclofop-methyl result in a rapid increase in population level resistance in Lolium rigidum. Theor Appl Genet 110: 1154-1166.

Neve P, Sadler J, Powles SB (2004). Multiple herbicide resistance in a glyphosate-resistant rigid ryegrass (Lolium rigidum) population. Weed Sci 52: 920-928.

Nietschke BS, Llewellyn RS, Reeves TG, Matthews JM, Powles SB (1996). Survey of herbicide resistance in ryegrass and wild oats. Proceedings of the 8th Australian Agronomy Conference, p 691.

Owen WJ (2000). Herbicide metabolism as a basis for selectivity. In: Roberts T (ed) Metabolism of Agrochemicals in Plants. John Wiley \& Sons Ltd: Chichester, UK, pp 211-258.

Patzoldt WL, Tranel PJ, Hager AG (2002). Variable herbicide responses among Illinois waterhemp (Amaranthus rudis and A. tuberculatus) populations. Crop Prot 21: 707-712. 
Powles SB, Shaner DL (2001). Herbicide Resistance and World Grains. CRC Press: Baton Rouge.

Preston C, Powles SB (2002). Evolution of herbicide resistance in weeds: initial frequency of target-site based resistance to acetolactate synthase-inhibiting in Lolium rigidum. Heredity 88: 8-13.

Preston C, Tardif FJ, Christopher JT, Powles SB (1996). Multiple resistance to dissimilar herbicide chemistries in a biotype of Lolium rigidum due to enhanced activity of several herbicide degrading enzymes. Pestic Biochem Phys 54: 123-134.
Seefeldt SS, Fuerst EP, Gealy DR, Shukla A, Irzyk GA, Devine M (1996). Mechanisms of resistance to diclofop of two wild oat (Avena fatua) biotypes from the Willamette Valley of Oregon. Weed Sci 44: 776-781.

Tardif FJ, Holtum JAM, Powles SB (1993). Occurrence of a herbicide-resistant acetyl-coenzyme A carboxylase mutant in annual ryegrass (Lolium rigidum) selected by sethoxydim. Planta 190: 176-181.

Tranel PJ, Wright TR (2002). Resistance of weeds to ALSinhibiting herbicides: what have we learned? Weed Sci 50: 700-712. 